\title{
Age-associated gene expression changes in the arcuate nucleus of male rhesus macaques
}

\author{
Dominique H Eghlidi', Vasilios T Garyfallou², Steven G Kohama² and \\ Henryk F Urbanski2,3,4,5
}

1Department of Neurology and Division of Sleep Medicine, Harvard Medical School, Beth Israel Deaconess Medical Center, Boston, Massachusetts, USA

2Division of Neuroscience, Oregon National Primate Research Center, Beaverton, Oregon, USA 3Division of Reproductive \& Developmental Sciences, Oregon National Primate Research Center, Beaverton, Oregon, USA

${ }^{4}$ Department of Behavioral Neuroscience, Oregon Health \& Science University, Portland, Oregon, USA

${ }^{5}$ Department of Physiology \& Pharmacology, Oregon Health \& Science University, Portland, Oregon, USA

Correspondence should be addressed to $\mathrm{H}$ F Urbanski

Email

urbanski@ohsu.edu

\begin{abstract}
The hypothalamic arcuate nucleus (ARC) represents a major component of the neuroendocrine reproductive axis and plays an important role in controlling the onset of puberty as well as age-associated reproductive senescence. Although significant gene expression changes have been observed in the ARC during sexual maturation, it is unclear what changes occur during aging, especially in males. Therefore, in the present study, we profiled the expression of reproduction-related genes in the ARC of young and old male rhesus macaques, as well as old males that had received 6 months of hormone supplementation (HS) in the form of daily testosterone and dehydroepiandrosterone; we also compared morning vs night ARC gene expression in the old males. Using Affymetrix gene microarrays, we found little evidence for age-associated expression changes for genes associated with the neuroendocrine reproductive axis, whereas using qRT-PCR, we detected a similar age-associated decrease in $P G R$ (progesterone receptor) that we previously observed in postmenopausal females. We also detected a sex-steroiddependent and age-associated decrease in androgen receptor $(A R)$ expression, with highest $A R$ levels being expressed at night (i.e., coinciding with the natural peak in daily testosterone secretion). Finally, unlike previous observations made in females, we did not find a significant age-associated increase in KISS1 (Kisspeptin) or TAC3 (Neurokinin $B$ ) expression in the ARC of males, most likely because the attenuation of circulating sex-steroid levels in the males was much less than that in postmenopausal females. Taken together, the data highlight some similarities and differences in ARC gene expression between aged male and female nonhuman primates.
\end{abstract}

Key Words
- aging
- androgen receptor
- circadian rhythms
- reproduction
- testosterone




\section{Introduction}

Neural circuits located in the hypothalamic arcuate nucleus (ARC) play an important role in regulating homeostatic and endocrine functions. By modulating the secretion of hormones from the anterior pituitary gland, neuropeptides released from the ARC can affect a wide range of physiological functions, including somatic growth, metabolism, lactation, stress and reproduction. The ARC also serves as an important feedback integration center for hormones produced by peripheral organs, especially sex steroids. During aging, this dynamic relationship between ARC neuropeptides and sex-steroid feedback changes markedly, and in the case of female humans and rhesus macaques, this is associated with the onset of menopause (Gilardi et al. 1997, Downs \& Urbanski 2006). However, little is known about the gene expression changes that occur in the human ARC during aging, in part because of the difficulty in obtaining quality mRNA from postmortem human brain tissue.

Like humans, rhesus macaques are long-lived diurnal primates that show many similar age-associated physiological and hormonal changes. For this reason, rhesus macaque studies represent a valuable translational animal model in which to gain insights about molecular changes that characterize neuroendocrine aging in humans. Some of the most dramatic changes observed in the ARC of aged female primates pertain to the control of the reproductive neuroendocrine axis and include an increase in the expression of genes that encode kisspeptin (KISS1) and tachykinin 3 (TAC3) and a decrease in the expression of the progesterone receptor gene (PGR) (Rance 2009, Eghlidi et al. 2010, Eghlidi \& Urbanski 2015). These gene expression changes in the neuroendocrine reproductive axis and steroid receptors have been shown to result from the marked decrease in circulating estradiol concentrations, rather than from aging per se, because they can be reversed by administration of exogenous estradiol (Bethea et al. 1996, Eghlidi et al. 2010, Eghlidi \& Urbanski 2015). Although age-related hormone changes also occur in males, the decrease in circulating sex-steroid concentrations is more gradual and less complete than that in females (Bremner et al. 1983, Down \& Urbanski 2006, Downs et al. 2008, Urbanski \& Sorwell 2012, Urbanski et al. 2014). Therefore, it is unclear if the ARC of male primates undergoes similar age-related gene expression changes as in females (Hrabovszky et al. 2011, 2012, Molnar et al. 2012, Hrabovszky 2014). The primary goal of the present study was to profile gene expression in the ARC of aging male rhesus macaques, with a special emphasis on genes associated with the neuroendocrine reproductive axis. To determine the sex-steroid dependence of the ageassociated changes, we also profiled gene expression in the ARC of old males supplemented with androgens for 6 months.

\section{Materials and methods}

\section{Animals}

Six young adult (age range 7-12 years) and 18 old (age range 21-26 years) male rhesus macaques (Macaca mulatta) were cared for by the Division of Comparative Medicine at the Oregon National Primate Research Center (ONPRC) in accordance with the National Research Council's Guide for the Care and Use of Laboratory Animals. The animals were housed indoors under controlled environmental conditions: $24^{\circ} \mathrm{C}$ temperature; 12 -h light:12-h darkness photoperiods with lights on at 07:00h. Meals were provided regularly at 08:00 h and 15:00 h (ZT1 and ZT8, respectively) (LabDiet High Protein Monkey Chow; LabDiet, Inc., St Louis, MO, USA) and supplemented with fresh fruit or vegetables; drinking water was available ad libitum. Procedures for care and treatment of the animals were in accordance with the methods approved by the Institutional Animal Care and Use Committee.

\section{Tissue collection}

In the main study, all of the postmortem brain tissue was collected in the morning, between 10:00 and 11:00 h. The animals were sedated with ketamine $(15-25 \mathrm{mg} / \mathrm{kg}$ i.m.) followed by pentobarbital sodium (25-30 mg/kg i.v.), a procedure consistent with the recommendations of the American Veterinary Medical Association's Panel on Euthanasia. Brains were collected after first flushing with $1 \mathrm{~L}$ of $0.9 \%$ saline via a cardiac catheter; the hypothalami were then blocked and preserved in RNAlater (Ambion) for 1-2 weeks. Subsequently, the ARC was bilaterally sub-dissected from a coronal slice of each hypothalamic block, by a single investigator and stored at $-80^{\circ} \mathrm{C}$. As previously described (Eghlidi et al. 2010), the boundaries for this tissue block included the exterior ventral edge of the hypothalamic median eminence, lateral cuts midway between the third ventricle and the optic nerve, an anterior cut along the posterior edge of the optic chiasma, a posterior cut just anterior to the mammillary bodies, and a cut $1 \mathrm{~mm}$ dorsal to the base of the third ventricle

Published by Bioscientifica Ltd. 
(i.e. based on stereotaxic coordinates, this represents the border between the ARC and the ventromedial hypothalamus).

\section{Experimental design}

The male monkeys were assigned to one of the following three groups: Young $(n=6)$, Old $(n=7)$ and Old HS $(n=6)$; in the latter group, the animals were given daily oral hormonal supplements (HS), comprising testosterone (T) and dehydroepiandrosterone (DHEA), for 6 months. $\mathrm{T}$ was administered at 19:00 h (12 mg/kg body weight) and two oral DHEA administrations were administered at 07:00 and 10:00 h (0.04 mg/kg body weight); both $\mathrm{T}$ and DHEA were obtained from Sigma-Aldrich. Previously, it had been shown that when $\mathrm{T}$ is administered orally in oil significant quantities bypass the liver, presumably because of reduced passage into the hepatic portal system and increased uptake by the lymphatic system, which elevate circulating $\mathrm{T}$ concentrations (Amory \& Bremner 2005). Consequently, as previously described (Urbanski et al. 2014, Urbanski 2017), we suspended the $\mathrm{T}$ in sesame oil at a concentration of $120 \mathrm{mg} / \mathrm{mL}$ and then mixed an appropriate amount depending on the animal's body weight with $\sim 12 \mathrm{~g}$ of chocolate or placed it inside a $5 \mathrm{~g}$ cookie, based on the animal's preference. Similarly, we suspended the DHEA in sesame oil $(10 \mathrm{mg} / \mathrm{mL})$ and mixed an appropriate amount with chocolate or placed it inside a cookie. This daily androgen supplementation paradigm was previously shown to recapitulate mean youthful circulating levels of DHEA sulfate (DHEAS), estradiol, estrone, $5 \alpha$-dihydrotestosterone and T, while preserving their characteristic circadian profiles (although not the underlying pulsatile patterns) (Urbanski et al. 2014). The old control animals did not receive control treats or vehicle but were otherwise exposed to the same environmental conditions. Using Affymetrix Rhesus Gene Chip 1.0 ST Arrays, we profiled all the genes in the ARC of male rhesus monkeys during aging and following $\mathrm{T}$ and DHEA supplementations. Next, we focused on steroid receptor and reproductive genes. Array data were corroborated using quantitative realtime polymerase chain reaction (qRT-PCR) to measure sex-steroid gene expression as well as KISS1 and TAC3, the genes that encode kisspeptin and tachykinin 3 (also known as neurokinin B (NKB)), respectively.

There is growing evidence from monkey and rodent studies that many genes show a circadian pattern of expression (Lemos et al. 2006, Zhang et al. 2014).
Consequently, we were concerned that by focusing our gene profiling on only one time-of-day (i.e. 10:00-11:00 h; ZT3-4), we may have missed significant age-related expression changes in genes that show a peak later in the day. To help address this issue, we also collected postmortem hypothalamic tissue from five old gonadintact male rhesus macaques at 22:00-23:00 h (ZT15-16), i.e. $12 \mathrm{~h}$ later in the day. As described previously, we similarly profiled gene expression in the ARC of these animals (Old PM) and compared the expression pattern to that observed in the morning in the Old controls (Old $\mathrm{AM})$. The animals in the ZT15-16 group were maintained under the same 12-h light:12-h darkness photoperiods as described previously. During the nighttime tissue collections, the animals' eyes were covered to prevent photic phase resetting via light input through the retina.

\section{RNA extraction and gene expression profiling}

RNA was isolated from the whole ARC using the RNeasy Plus Universal Mini Kit (Qiagen) with two QIAcube Automation Systems (Qiagen). An Agilent 2100 Bioanalyzer (Agilent Technologies) was used to determine the quality of the RNA and a NanoDrop 2000 (Thermo Fisher Scientific) was used to determine the concentration. Gene expression profiling was performed by the OHSU Gene Profiling Shared Resource. Briefly, target labeling was performed using total RNA samples that were prepared for array hybridization by synthesizing cDNA using the Ovation Pico WTA RNA Amplification System v.2 (NuGEN Technologies). Array hybridization and processing was performed by injecting the hybridization cocktail into a cartridge containing the GeneChip Rhesus Gene 1.0 ST array (Affymetrix) containing 37,375 gene-level probe sets. Arrays were incubated, washed and stained on a GeneChip Fluidics Station 450 (Affymetrix) using the Hybridization Wash and Stain kit (Affymetrix). They were then scanned using the GeneChip Scanner 3000 7G with an autoloader (Affymetrix). Each array file was then analyzed using the Affymetrix Command Console v.3.1.1 software, and expression analysis was performed using Affymetrix Expression Console Software 1.4. Probe cell intensity files (CEL) for each of the experimental samples were uploaded into the Affymetrix Expression Console Software 1.4, and a multi-array analysis incorporating all the samples of the study group was performed using the Robust Multi-Array Average (RMA)-Sketch normalization, and a summarization algorithm for all exon transcripts was generated for further comparisons using the Affymetrix Expression Console Software 1.4.

Published by Bioscientifica Ltd. 
Table 1 TaqMan qRT-PCR primer and probe nucleotide sequences $\left(5^{\prime}-3^{\prime}\right)$.

\begin{tabular}{|c|c|}
\hline Gene name & Primer sequences \\
\hline \multirow[t]{2}{*}{$A R$} & (F) AAAATCCCACATCCTGCTCAA \\
\hline & (R) CAGGTCAAAAGTGAACTGATGCA \\
\hline \multirow[t]{2}{*}{ ESR1 } & (F) ACAAGATCACAGACACTTTGATCCA \\
\hline & (R) CCTGATGTGGGAGAGGATGAG \\
\hline \multirow[t]{2}{*}{ ESR2 } & (F) GATCACTAGAACACACCTTACCTGTA \\
\hline & (R) GGTGCAACGGTTCCCACTAA \\
\hline \multirow[t]{2}{*}{$P G R$} & (F) CATGTCAGTGGGCAGATGCT \\
\hline & (R) TGCCACATGGTAAGGCATAATG \\
\hline \multirow[t]{2}{*}{ KISS1 } & (F) AGAAAAGGTGGCCTCTGTGGA \\
\hline & (R) AGGCTCTGCTCCCACGG \\
\hline \multirow[t]{2}{*}{ TAC3 } & (F) GAGCCACAGGAGGAGATGGTT \\
\hline & (R) TCCAGAGATGAGTGGCTTTTGA \\
\hline \multirow{2}{*}{ RPL13A } & (F) TCACGAGGTTGGCTGGAAGT \\
\hline & (R) GATCTTGGCTTTCTCCTTCCTCTT \\
\hline
\end{tabular}

Probe sequences
6FAM-TGCAGCCTATTGCGAGAG-MGB
6FAM-AGGCCTGACCCTGCAG-MGB
6FAM-AGAGACATTGAAAAGGAAG-MGB
6FAM-CTGAATGAACAGCGGATG-MGB
6FAM-CAGGCCAGCAGCTGGAATCCCTG-MGB
6FAM-ACAGCAAGAGGGATCT-MGB
6FAM-CCAGGCAGTGACAGCCACCTTGG-MGB

GenBank accession ID. AF092930

571040

NM_001265821

XM_001095317

AY823262

XM 001115535

XM_001115079

Reference sequences for each of the target genes can be accessed through GenBank accession IDs.

\section{TaqMan quantitative real-time polymerase chain reaction (qRT-PCR)}

As previously described (Eghlidi et al. 2010, Eghlidi \& Urbanski 2015), a QuantStudio 12K Flex thermocycler was used for qRT-PCR (Life Technologies). Initially, $500 \mathrm{ng}$ of ARC RNA was converted to cDNA using the SuperScript III First-Strand Synthesis System for RT-PCR (Invitrogen Life Technologies). Next, pooled cDNA was used to create standard curves for each gene, and the experimental samples were subsequently diluted to fall within the linear part of the curve. The PCR mixtures contained $5 \mu \mathrm{L}$ TaqMan Gene Expression Master Mix, $2.15 \mu \mathrm{L}$ of water, $0.3 \mu \mathrm{L}$ of each specific forward and reverse primer (300 $\mathrm{nM}$ final concentration), $0.25 \mu \mathrm{L}$ of specific probe $(250 \mathrm{nM}$ final concentration) and $2 \mu \mathrm{L}$ of cDNA. The qRT-PCR reaction sequence included a 10 -min incubation at $95^{\circ} \mathrm{C}$, followed by 40 cycles of $15 \mathrm{~s}$ at $95^{\circ} \mathrm{C}, 1 \mathrm{~min}$ at $60^{\circ} \mathrm{C}, 1 \mathrm{~min}$ at $60^{\circ} \mathrm{C}$ and $15 \mathrm{~s}$ at $95^{\circ} \mathrm{C}$. For AR, ESR1, ESR2, PGR, KISS1 and TAC3, the automatic baseline and threshold levels were determined by QuantStudio 12K Flex thermocycler detection system software, and the final expression values were normalized to RPL13A. For each gene, samples were examined on the same 384-well optical plate in triplicate for each animal. A negative control included the omission of cDNA templates from the reaction mixture. The primer and probe base sequences used for the qRT-PCR are listed in Table 1.

\section{Statistics}

ANOVAs were used to assess differences between groups. A false discovery rate (FDR) correction for multiple comparisons was used for whole genome comparisons (Benjamini \& Hochberg 1995). A Bonferroni correction was used when comparing the Young, Old HS and Old PM groups to the Old AM controls.

\section{Results}

First, whole transcriptome expression was compared between Young and Old AM controls, as well as between Old AM controls and Old HS animals, using Affymetrix

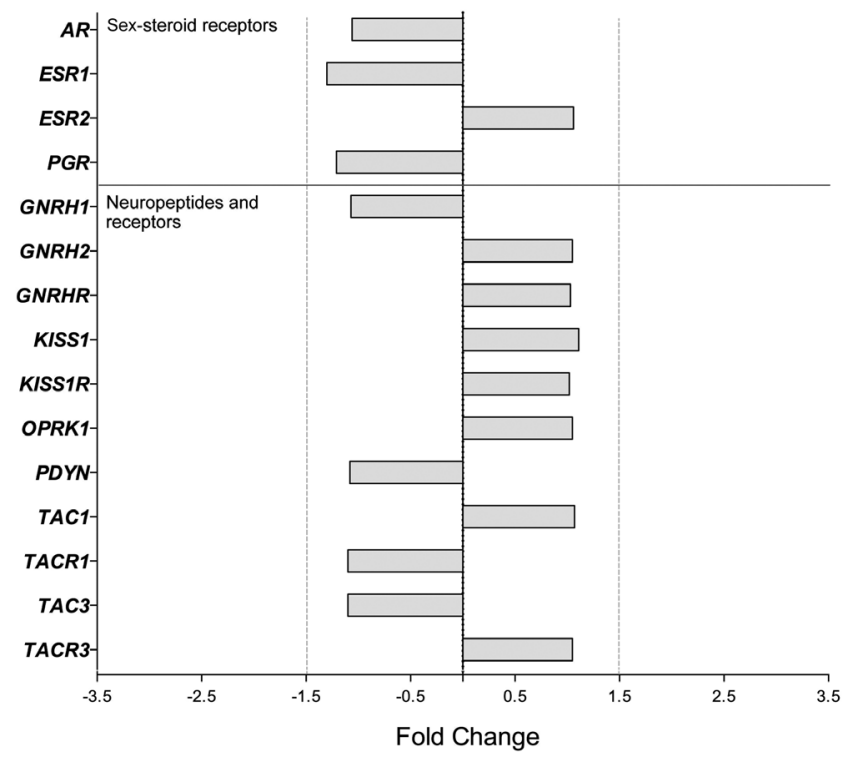

Figure 1

Gene expression in the ARC of male rhesus macaques: effect of age on genes encoding sex-steroid receptors and reproduction-related neuropeptide systems. Fold change (FC) differences in expression are show for the Old AM controls relative to the Young animals. No significant differences were detected $(P>0.05)$.

Published by Bioscientifica Ltd. http://jme.endocrinology-journals.org DOI: 10.1530/JME-17-0094 


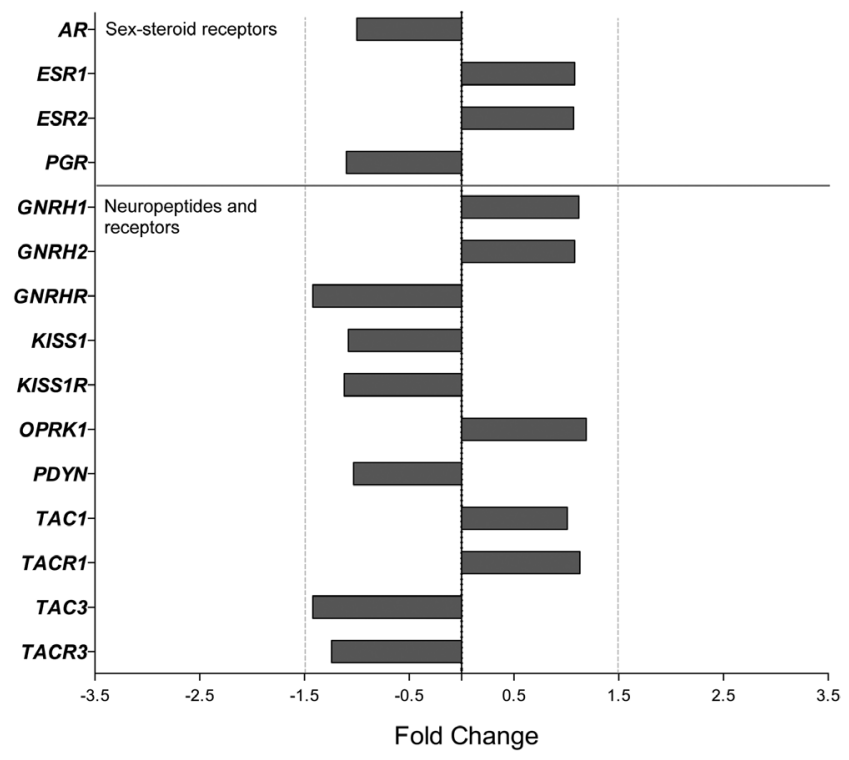

Figure 2

Gene expression in the ARC of male rhesus macaques: effect of androgen supplementation on genes encoding sex-steroid receptors and reproduction-related neuropeptide systems. Fold-change (FC) differences in expression are show for the Old HS animals relative to the Old AM controls. No significant differences were detected $(P>0.05)$.
Expression Console Software 1.4, with additional annotation provided by the ONPRC Collaborative Genetic Resource and Bioinformatics Units. The data were aligned with the Expression Console Output and to correct for discrepancies in the annotations, they were compared to annotations using Ingenuity Pathway Analysis and the NetAffx Analysis Center. After applying a FDR correction to the results, none of the 37,375 gene transcripts showed major $(>1.5$ fold) changes in expression between Young and Old or Old vs Old HS animals (FDR corrected $P$ value $>0.05$; data not shown). Importantly, genes associated with the neuroendocrine reproductive axis continued to be constitutively expressed during aging and appeared to be unaffected by the $\mathrm{HS}(\mathrm{FC}<1.5, P>0.05$, Figs 1 and 2 and Table 2). Using qRT-PCR, we confirmed that ESR1, ESR2, KISS1 and TAC3 expression did not change during aging or in response to HS ( $P>0.05$, Table 3$)$, whereas $P G R$ and $A R$ showed a significant $(P<0.05)$ decrease in the old animals; $A R$ expression in the Old HS animals was significantly higher than that in the age-matched Old controls, suggesting that the age-associated decrease may stem from attenuated circulating androgen levels.

Because so few genes in the ARC showed obvious age-related changes, we wondered if we may have missed

Table 2 GeneChip evaluation of gene expression in the male rhesus macaque arcuate nucleus.

\begin{tabular}{|c|c|c|c|c|c|c|c|}
\hline \multirow[b]{2}{*}{ Gene symbol } & \multirow[b]{2}{*}{ Description } & \multirow[b]{2}{*}{ ID } & \multicolumn{3}{|c|}{ AM } & \multicolumn{2}{|l|}{ PM } \\
\hline & & & Old (Control) & Young & Old HS & Old & $P$ value \\
\hline \multicolumn{8}{|c|}{ Sex-steroid receptors } \\
\hline$A R$ & Androgen receptor & 13806207 & $5.81 \pm 0.10$ & $5.89 \pm 0.05$ & $5.81 \pm 0.08$ & $6.42 \pm 0.08 *$ & 0.0001 \\
\hline ESR1 & Estrogen receptor 1 & 13827480 & $5.54 \pm 0.09$ & $5.92 \pm 0.10$ & $5.65 \pm 0.06$ & $5.86 \pm 0.28$ & 0.2026 \\
\hline ESR2 & Estrogen receptor 2 & 13784393 & $4.64 \pm 0.13$ & $4.56 \pm 0.06$ & $4.74 \pm 0.11$ & $4.50 \pm 0.06$ & 0.3874 \\
\hline$P G R$ & Progesterone receptor & 13658473 & $6.89 \pm 0.09$ & $7.17 \pm 0.08$ & $6.75 \pm 0.05$ & $6.46 \pm 0.25$ & 0.0090 \\
\hline \multicolumn{8}{|c|}{ Neuropeptides and receptors } \\
\hline GNRH1 & $\begin{array}{l}\text { Gonadotropin-releasing } \\
\text { hormone } 1\end{array}$ & 13790870 & $6.94 \pm 0.15$ & $7.03 \pm 0.16$ & $7.10 \pm 0.28$ & $7.58 \pm 0.35$ & 0.2997 \\
\hline GNRH2 & $\begin{array}{l}\text { Gonadotropin-releasing } \\
\text { hormone } 2\end{array}$ & 13606683 & $5.46 \pm 0.11$ & $5.38 \pm 0.15$ & $5.57 \pm 0.09$ & $5.10 \pm 0.16$ & 0.1015 \\
\hline GNRHR & $\begin{array}{l}\text { Gonadotropin-releasing } \\
\text { hormone receptor }\end{array}$ & 13752156 & $4.31 \pm 0.40$ & $4.27 \pm 0.43$ & $3.81 \pm 0.41$ & $5.28 \pm 0.75$ & 0.2657 \\
\hline KISS1 & Kisspeptin & 13589384 & $5.28 \pm 0.07$ & $5.14 \pm 0.15$ & $5.18 \pm 0.11$ & $5.06 \pm 0.19$ & 0.6768 \\
\hline KISS1R & Kisspeptin receptor & 13820906 & $6.18 \pm 0.13$ & $6.14 \pm 0.09$ & $6.01 \pm 0.14$ & $5.93 \pm 0.11$ & 0.4600 \\
\hline OPRK1 & Opioid receptor, kappa 1 & 13791718 & $6.56 \pm 0.11$ & $6.50 \pm 0.12$ & $6.82 \pm 0.09$ & $6.74 \pm 0.09$ & 0.1592 \\
\hline$P D Y N$ & Prodynorphin & 13612278 & $6.38 \pm 0.10$ & $6.50 \pm 0.13$ & $6.35 \pm 0.18$ & $6.74 \pm 0.19$ & 0.3140 \\
\hline TAC1 & Tachykinin 1 & 13735408 & $7.63 \pm 0.19$ & $7.54 \pm 0.20$ & $7.65 \pm 0.09$ & $7.64 \pm 0.34$ & 0.9802 \\
\hline TACR1 & Tachykinin receptor 1 & 13644855 & $4.49 \pm 0.20$ & $4.62 \pm 0.12$ & $4.67 \pm 0.23$ & $4.74 \pm 0.18$ & 0.8168 \\
\hline TAC3 & Tachykinin 3 & 13625903 & $6.40 \pm 0.28$ & $6.53 \pm 0.21$ & $5.89 \pm 0.15$ & $6.01 \pm 0.47$ & 0.3154 \\
\hline TACR3 & Tachykinin receptor 3 & 13757467 & $4.48 \pm 0.10$ & $4.41 \pm 0.16$ & $4.17 \pm 0.08$ & $4.38 \pm 0.32$ & 0.5849 \\
\hline
\end{tabular}

Affymetrix GeneChip rhesus 1.0 ST arrays were used to profile gene expression in the arcuate nucleus. Values represent means \pm s.E.M. of bi-weighted average signal intensity.

${ }^{*} P<0.05$, ANOVA with post hoc Bonferroni adjustment, relative to the Old (Control) group.

AM, morning necropsy; HS, 6 months of T and DHEA hormone supplementation; PM, evening necropsy.

http://jme.endocrinology-journals.org DOI: 10.1530/JME-17-0094 (c) 2017 Society for Endocrinology Printed in Great Britain
Published by Bioscientifica Ltd 
Table 3 qRT-PCR evaluation of gene expression in the male rhesus macaque arcuate nucleus.

\begin{tabular}{|c|c|c|c|c|c|c|c|}
\hline \multirow[b]{2}{*}{ Gene symbol } & \multirow[b]{2}{*}{ Description } & \multirow[b]{2}{*}{ GenBank ID } & \multicolumn{3}{|c|}{ AM } & \multicolumn{2}{|l|}{ PM } \\
\hline & & & Old (Control) & Young & Old HS & Old & $P$ value \\
\hline \multicolumn{8}{|c|}{ Sex-steroid receptors } \\
\hline$A R$ & Androgen receptor & AF092930 & $0.87 \pm 0.10$ & $1.26 \pm 0.05 *$ & $1.15 \pm 0.04 *$ & $1.24 \pm 0.10 *$ & 0.0052 \\
\hline ESR1 & Estrogen receptor 1 & S71040 & $1.16 \pm 0.25$ & $0.98 \pm 0.18$ & $0.84 \pm 0.08$ & $0.84 \pm 0.07$ & 0.5705 \\
\hline ESR2 & Estrogen receptor 2 & NM_001265821 & $0.86 \pm 0.13$ & $1.07 \pm 0.09$ & $0.94 \pm 0.09$ & $1.06 \pm 0.06$ & 0.4096 \\
\hline PGR & Progesterone receptor & XM_001095317 & $0.89 \pm 0.10$ & $1.51 \pm 0.08 *$ & $1.09 \pm 0.09$ & $1.07 \pm 0.25$ & 0.0211 \\
\hline \multicolumn{8}{|c|}{ Neuropeptides } \\
\hline KISS1 & Kisspeptin & AY823262 & $1.21 \pm 0.18$ & $1.94 \pm 0.37$ & $1.00 \pm 0.20$ & $1.83 \pm 0.87$ & 0.3570 \\
\hline TAC3 & Tachykinin 3 & XM_001115535 & $0.44 \pm 0.06$ & $0.66 \pm 0.11$ & $0.36 \pm 0.07$ & $0.59 \pm 0.25$ & 0.3220 \\
\hline
\end{tabular}

GeneChip array data were corroborated by qRT-PCR expression analysis. Values represent means \pm S.E.M.

${ }^{*} P<0.05$, ANOVA with post hoc Bonferroni adjustment, relative to the Old (Control) group.

AM, morning necropsy; HS, 6 months of T and DHEA hormone supplementation; PM, evening necropsy.

them because they occur during the night rather than during the day (i.e., when postmortem tissues are usually collected). To help address this concern, we also collected brain tissue from Old males at night (PM) and compared the ARC gene expression profiles with those from Old males in the morning (AM). Although the steroid receptor $A R$ and central reproductive genes GNRH1 and GNRHR showed $>1.5$-fold greater expression in the evening $(\mathrm{PM}, 22: 00-23: 00 \mathrm{~h})$ than that in the morning (AM, 10:00-11:00 h) (Fig. 3), only the diurnal difference in $A R$ expression was statistically significant $(P<0.05$, Table 3$)$.

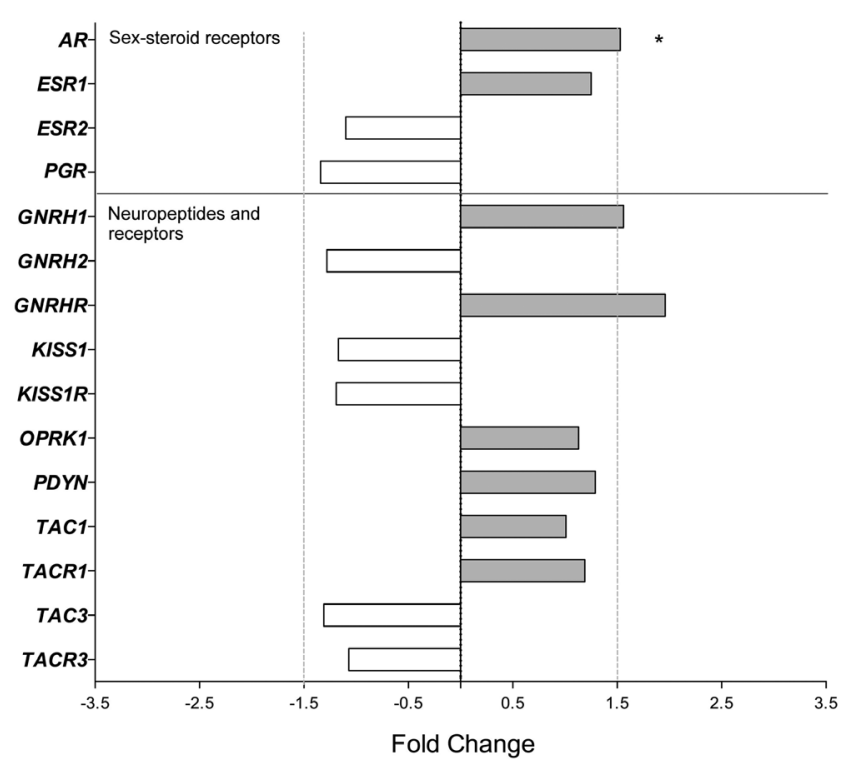

Figure 3

Gene expression in the ARC of male rhesus macaques: effect of time of day on genes encoding sex-steroid receptors and reproduction-related neuropeptide systems. Fold-change (FC) differences in expression are shown for the Old PM animals (at 22:00-23:00 h) relative to the Old AM controls (at 10:00-11:00 h). ${ }^{*} P<0.05$

http://jme.endocrinology-journals.org DOI: 10.1530/JME-17-0094

\section{Discussion}

In contrast to female primates, males (humans and monkeys) show a gradual and incomplete attenuation of their circulating sex-steroid concentrations during aging (Vermeulen et al. 1972, Marrama et al. 1982, Bremner et al. 1983, Tenover et al. 1988, Cooke et al. 1993, Harman et al. 2001, Feldman et al. 2002, Hardy \& Schlegel 2004, Sitzmann et al. 2014, Urbanski et al. 2014). Therefore, it is plausible that age-related sex-differences exist in brain areas that integrate the positive and negative feedback actions of sex steroids on the reproductive neuroendocrine axis. To help resolve this issue, we used rhesus macaquespecific gene microarrays and qRT-PCR, to assess changes in the ARC transcriptome of males during aging and in response to HS. Although all of the genomic sex-steroid receptors were clearly expressed in the ARC of males, only $A R$ and $P G R$ showed evidence of age-associated change. Using qRT-PCR (Eghlidi \& Urbanski 2015) and in situ hybridization (Bethea et al. 1996), we previously demonstrated sex-steroid-dependent regulation of $P G R$ expression in the ARC of young and old female rhesus macaques, and so were expecting to observe a similar age-related decrease in males. On the other hand, the circulating estradiol levels in all of our males were between 15 and $30 \mathrm{pg} / \mathrm{mL}$ (Urbanski et al. 2014), which is similar to the estradiol levels that we typically observed in females during the early follicular phase of the menstrual cycle, but lower than what is observed during the late follicular phase, and much higher than what is observed after menopause (Downs \& Urbanski 2006). Consequently, the relatively subtle differences in circulating estradiol levels seen between the Young, Old and Old HS males precluded any major sex-steroid-dependent differences in $P G R$ gene expression. It should be emphasized, however, that the current methodologies did not distinguish between the

Published by Bioscientifica Ltd. 
two different PGR isoforms ( $P G R-A$ and $P G R-B$ ), which have different expression patterns and functions (Vegeto et al. 1993, Duffy et al. 1997, Mulac-Jericevic et al. 2000, Richer et al. 2002, Stouffer 2003). Therefore, we cannot rule out the possibility of compensatory alterations in the expression of $P G R-A$ or $P G R-B$ during aging.

In a previous study, a ribonuclease protection assay (using the same AR target sequence that we used in our qRT-PCR) showed no effect of testosterone on the hypothalamic expression of $A R$ in male young rhesus macaques (Abdelgadir et al. 1999). Our results, however, suggest that there may be hormonal regulation of $A R$, at least during aging. The reason for this discrepancy is unclear but may stem from differences in baseline androgen levels of young and old males or in differences in the hormonal supplementation paradigms. Because testosterone and DHEA both show circadian patterns of release as well as a significant age-associated decline in circulating levels, our androgen supplementation paradigm was designed to keep the circulating levels of these two hormones in a physiological range without perturbing their characteristic 24-h patterns (Urbanski et al. 2014). We also show that $A R$ expression is significantly higher at night, i.e., a time when circulating testosterone levels are at their peak, even in aged primates (Urbanski 2011, Urbanski \& Sorwell 2012, Sitzmann et al. 2014, Urbanski et al. 2014). Taken together, our findings show that $A R$ expression in the male ARC undergoes similar steroid-dependent ageassociated changes as does $P G R$ in the ARC of females and may serve a similar physiological role as a primary mediator of negative gonadal feedback during aging.

Lastly, an important finding from the present study was the insignificant difference in KISS1 and TAC3 expression between the Young and Old and between the Old vs the Old HS animals. Previous immunohistochemical examination of the kisspeptin and tachykinin 3 (a.k.a., neurokinin B $(\mathrm{NKB}))$ neuronal system in the ARC of men showed an age-associated increase in KISS1 and TAC3 fiber density and increased contacts with GnRH neurons in the median eminence (Hrabovszky et al. 2011, Molnar et al. 2012). In addition, quantitative analysis of KISS1 and TAC3 expression in the ARC revealed sex-steroid-dependent increases in old ovariectomized females (Kim et al. 2009, Rance 2009, Eghlidi et al. 2010, Eghlidi \& Urbanski 2015). Both these findings suggest that the attenuated circulating androgen levels of healthy old males may be too modest to stimulate a significant rise in KISS1 and TAC3 at the mRNA level, although more physiologically relevant changes at the translational level cannot be ruled out. GNRH1, GNRH2 and GNRHR showed no obvious agerelated change, underscoring our previous observations that in healthy rhesus macaques, testicular function continues well into old age (Sitzmann et al. 2014), and circulating sex-steroid concentrations do not show such an abrupt or complete decrease as do menopausal females (Downs \& Urbanski 2006, Urbanski 2011, Urbanski \& Sorwell 2012, Sitzmann et al. 2014, Urbanski et al. 2014).

It is plausible that the negative gene array results reflect relative insensitivity of the methodology at detecting subtle gene expression changes, compared to qRT-PCR. Overall, however, the data from the present study show that gene expression in the ARC of male rhesus macaques is largely resistant to aging, especially genes that are associated with the neuroendocrine reproductive axis. Furthermore, the results largely agree with recent observations made in female rhesus macaques showing that the overall cytoarchitecture and sex-steroid receptor expression in the hypothalamus undergo relatively few changes with age and hormone supplementation (Naugle et al. 2014, 2016).

Declaration of interest

The authors declare that there is no conflict of interest that could be perceived as prejudicing the impartiality of the research reported.

\section{Funding}

This work was supported by National Institutes of Health grants: R01 AG029612, R01 AG-036670, T32 HL-007901, U42 OD-010426 and P51 OD-011092.

\section{Author contribution statement}

D H E performed experiments, analyzed the data and prepared the manuscript. V T G executed the study and helped with the data analysis. H F U and S G K designed and executed the study and helped with preparation of the manuscript.

\section{Acknowledgements}

The authors are grateful to the ONPRC Division of Comparative Medicine for assistance with care of the animals. They would also like to thank the ONPRC Molecular and Cell Biology Core for assistance with mRNA quantitation, the OHSU Gene Profiling Shared Resource for evaluating the gene expressions and the Harvard Medical School Countway Library Bioinformatics for assistance with the annotation alignment.

\section{References}

Abdelgadir SE, Roselli CE, Choate JV \& Resko JA 1999 Androgen receptor messenger ribonucleic acid in brains and pituitaries of male rhesus monkeys: studies on distribution, hormonal control, and relationship to luteinizing hormone secretion. Biology of Reproduction 60 1251-1256. (doi:10.1095/biolreprod60.5.1251)
๑ 2017 Society for Endocrinology Printed in Great Britain
Published by Bioscientifica Ltd 
Amory JK \& Bremner WJ 2005 Oral testosterone in oil plus dutasteride in men: a pharmacokinetic study. Journal of Clinical Endocrinology and Metabolism 90 2610-2617. (doi:10.1210/jc.2004-1221)

Benjamini Y \& Hochberg Y 1995 Controlling the false discovery rate: a practical and powerful approach to multiple testing. Journal of the Royal Statistics Society B $\mathbf{5 7}$ 289-300.

Bethea CL, Brown NA \& Kohama SG 1996 Steroid regulation of estrogen and progestin receptor messenger ribonucleic acid in monkey hypothalamus and pituitary. Endocrinology 137 4372-4383. (doi:10.1210/endo.137.10.8828498)

Bremner WJ, Vitiello MV \& Prinz PN 1983 Loss of circadian rhythmicity in blood testosterone levels with aging in normal men. Journal of Clinical Endocrinology and Metabolism 56 1278-1281. (doi:10.1210/ jcem-56-6-1278)

Cooke RR, McIntosh JE \& McIntosh RP 1993 Circadian variation in serum free and non-SHBG-bound testosterone in normal men: measurements, and simulation using a mass action model. Clinical Endocrinology 39 163-171. (doi:10.1111/j.1365-2265.1993.tb01769.x)

Downs JL \& Urbanski HF 2006 Neuroendocrine changes in the aging reproductive axis of female rhesus macaques (Macaca mulatta). Biology of Reproduction 75 539-546. (doi:10.1095/ biolreprod.106.051839)

Downs JL, Mattison JA, Ingram DK \& Urbanski HF 2008. Effect of age and caloric restriction on circadian adrenal steroid rhythms in rhesus macaques. Neurobiology of Aging 29 1412-1422. (doi:10.1016/j. neurobiolaging.2007.03.011)

Duffy DM, Wells TR, Haluska GJ \& Stouffer RL 1997 The ratio of progesterone receptor isoforms changes in the monkey corpus luteum during the luteal phase of the menstrual cycle. Biology of Reproduction 57 693-699. (doi:10.1095/biolreprod57.4.693)

Eghlidi DH, Haley GE, Noriega NC, Kohama SG \& Urbanski HF 2010 Influence of age and 17beta-estradiol on kisspeptin, neurokinin B, and prodynorphin gene expression in the arcuate-median eminence of female rhesus macaques. Endocrinology 151 3783-3794. (doi:10.1210/en.2010-0198)

Eghlidi DH \& Urbanski HF 2015 Effects of age and estradiol on gene expression in the rhesus macaque hypothalamus. Neuroendocrinology 101 236-245. (doi:10.1159/000381063)

Feldman HA, Longcope C, Derby CA, Johannes CB, Araujo AB, Coviello $\mathrm{AD}$, Bremner WJ \& McKinlay JB 2002 Age trends in the level of serum testosterone and other hormones in middle-aged men: longitudinal results from the Massachusetts male aging study. Journal of Clinical Endocrinology and Metabolism 87 589-598. (doi:10.1210/ jcem.87.2.8201)

Gilardi KV, Shideler SE, Valverde CR, Roberts, JA \& Lasley BL 1997 Characterization of the onset of menopause in the rhesus macaque. Biology of Reproduction 57 335-340. (doi:10.1095/biolreprod57.2.335)

Hardy MP \& Schlegel PN 2004 Testosterone production in the aging male: where does the slowdown occur? Endocrinology 145 4439-4440. (doi:10.1210/en.2004-0888)

Harman SM, Metter EJ, Tobin JD, Pearson J \& Blackman MR 2001 Longitudinal effects of aging on serum total and free testosterone levels in healthy men. Baltimore longitudinal study of aging. Journal of Clinical Endocrinology and Metabolism 86 724-731. (doi:10.1210/ jcem.86.2.7219)

Hrabovszky E, Molnár CS, Sipos MT, Vida B, Ciofi P, Borsay BA, Sarkadi L, Herczeg L, Bloom SR, Ghatei MA, et al. 2011 Sexual dimorphism of kisspeptin and neurokinin B immunoreactive neurons in the infundibular nucleus of aged men and women Frontiers in Endocrinology 2 80. (doi:10.3389/fendo.2011.00080)

Hrabovszky E, Sipos MT, Molnár CS, Ciofi P, Borsay BÁ, Gergely P, Herczeg L, Bloom SR, Ghatei MA, Dhillo WS, et al. 2012 Low degree of overlap between kisspeptin, neurokinin $\mathrm{B}$, and dynorphin immunoreactivities in the infundibular nucleus of young male human subjects challenges the KNDy neuron concept. Endocrinology 153 4078-4989.

Hrabovszky E 2014 Neuroanatomy of the human hypothalamic kisspeptin system. Neuroendocrinology 99 33-48. (doi:10.1159/000356903)

Kim W, Jessen HM, Auger AP \& Terasawa E 2009 Postmenopausal increase in KiSS-1, GPR54, and luteinizing hormone releasing hormone (LHRH-1) mRNA in the basal hypothalamus of female rhesus monkeys. Peptides 30 103-110. (doi:10.1016/j. peptides.2008.06.005)

Lemos DR, Downs JL \& Urbanski HF 2006 Twenty-four hour rhythmic gene expression in the rhesus macaque adrenal gland. Molecular Endocrinology 20 1164-1176. (doi:10.1210/me.2005-0361)

Marrama P, Carani C, Baraghini GF, Volpe A, Zini D, Celani MF \& Montanini V 1982 Circadian rhythm of testosterone and prolactin in the ageing. Maturitas 4 131-138. (doi:10.1016/03785122(82)90039-1)

Molnár CS, Vida B, Sipos MT, Ciofi P, Borsay BÁ, Rácz K, Herczeg L, Bloom SR, Ghatei MA, Dhillo WS, et al. 2012 Morphological evidence for enhanced kisspeptin and neurokinin B signaling in the infundibular nucleus of the aging man. Endocrinology $\mathbf{1 5 3}$ 5428-5439. (doi:10.1210/en.2012-1739)

Mulac-Jericevic B, Mullinax RA, DeMayo FJ, Lydon JP \& Conneely OM 2000 Subgroup of reproductive functions of progesterone mediated by progesterone receptor-B isoform. Science $\mathbf{2 8 9}$ 1751-1754. (doi:10.1126/science.289.5485.1751)

Naugle MM, Nguyen LT, Merceron TK, Filardo E, Janssen WG, Morrison JH, Rapp PR \& Gore AC 2014 G-protein coupled estrogen receptor, estrogen receptor $\alpha$, and progesterone receptor immunohistochemistry in the hypothalamus of aging female rhesus macaques given long-term estradiol treatment. Journal of Experimental Zoology Part A Ecological Genetics and Physiology 321 399-414. (doi:10.1002/jez.1871)

Naugle MM, Lozano SA, Guarraci FA, Lindsey LF, Kim JE, Morrison JH, Janssen WG, Yin W \& Gore AC 2016 Age and long-term hormone treatment effects on the ultrastructural morphology of the median eminence of female rhesus macaques. Neuroendocrinology $\mathbf{1 0 3}$ 650-664. (doi:10.1159/000442015)

Rance NE 2009 Menopause and the human hypothalamus: evidence for the role of kisspeptin/neurokinin B neurons in the regulation of estrogen negative feedback. Peptides 30 111-122. (doi:10.1016/j. peptides.2008.05.016)

Richer JK, Jacobsen BM, Manning NG, Abel MG, Wolf DM \& Horwitz KB 2002 Differential gene regulation by the two progesterone receptor isoforms in human breast cancer cells. Journal of Biological Chemistry 277 5209-5218. (doi:10.1074/jbc.M110090200)

Sitzmann BD, Brown DI, Garyfallou VT, Mattison JA, Ingram DK, Roth GS, Ottinger MA \& Urbanski HF 2014 Impact of moderate calorie restriction on testicular morphology and endocrine function in adult rhesus macaques (Macaca mulatta). Age 36 183-197. (doi:10.1007/ s11357-013-9563-6)

Stouffer RL 2003 Progesterone as a mediator of gonadotrophin action in the corpus luteum: beyond steroidogenesis. Human Reproduction Update 9 99-117. (doi:10.1093/humupd/dmg016)

Tenover JS, Matsumoto AM, Clifton DK \& Bremner WJ 1988 Age-related alterations in the circadian rhythms of pulsatile luteinizing hormone and testosterone secretion in healthy men. Journal of Gerontology $\mathbf{4 3}$ M163-M169. (doi:10.1093/geronj/43.6.M163)

Urbanski HF 2011 Role of circadian neuroendocrine rhythms in the control of behavior and physiology. Neuroendocrinology 93 211-222. (doi:10.1159/000327399)

Urbanski HF \& Sorwell K 2012 Age-related changes in neuroendocrine rhythmic function in the rhesus macaque. Age 34 1111-1121. (doi:10.1007/s11357-011-9352-z) http://jme.endocrinology-journals.org

DOI: 10.1530/JME-17-0094
() 2017 Society for Endocrinology Printed in Great Britain
Published by Bioscientifica Ltd 
Urbanski HF, Sorwell KG, Garyfallou VT, Garten J, Weiss A, Renner L, Neuringer M \& Kohama SG 2014 Androgen supplementation during aging: development of a physiologically appropriate protocol. Rejuvenation Research 17 150-153. (doi:10.1089/rej.2013.1518)

Urbanski HF 2017 Effect of androgen supplementation on 24-hour activity-rest patterns of aged male rhesus macaques. Neurobiology of Aging 54 100-102. (doi:10.1016/j.neurobiolaging.2017.02.020)

Vegeto E, Shahbaz MM, Wen DX, Goldman ME, O'Malley BW \& McDonnell DP 1993 Human progesterone receptor A form is a cell- and promoter-specific repressor of human progesterone receptor B function. Molecular Endocrinology 7 1244-1255. (doi:10.1210/ me.7.10.1244)

Vermeulen A, Rubens R \& Verdonck L 1972 Testosterone secretion and metabolism in male senescence. Journal of Clinical Endocrinology and Metabolism 34 730-735. (doi:10.1210/jcem-34-4-730)

Zhang R, Lahens NF, Ballance HI, Hughes ME \& Hogenesch JB 2014 A circadian gene expression atlas in mammals: implications for biology and medicine. PNAS 111 16219-16224. (doi:10.1073/pnas.1408886111)

Received in final form 7 June 2017

Accepted 14 June 2017

Accepted Preprint published online 14 June 2017
Published by Bioscientifica Ltd. 